\title{
Elements and Steps of E-Learning Benchmarking Model for Higher Education Institutions
}

\author{
Jirasak Sae-Khow ${ }^{1}$, Onjaree Na-Takuatoong ${ }^{2}$, Jintavee Khlaisang ${ }^{2}$ \\ ${ }^{1}$ Faculty of Education, Suratthani Rajabhat University, Suratthani, Thailand; ${ }^{2}$ Division of Educational Communications and Tech- \\ nology, Chulalongkorn University, Bangkok, Thailand. \\ Email: jirasak_cu@hotmail.com
}

Received October 2013

\begin{abstract}
The purposes of this research were to 1) develop of an e-learning benchmarking model for higher education institutions; 2) analyze and synthesize e-learning indicators for e-learning benchmarking model. The research was conducted using the research and development methods. The result shows that there are eight elements of e-learning benchmarking model: 1) team/staffs 2) benchmarking's title 3) comparative companies 4) benchmarking indicators 5) data collection method 6) analysis data and results 7) report of results and 8) action plan development. Moreover, four steps of benchmarking model will be used in this research. "Plan" is the step of setting team for benchmarking title and choosing the company to collect the benchmarking while "Do" is a field study in order to analyze and collect each indicator. The step "Check" presents the data to stakeholders and set the purposes of action plan. Finally, "Act" which is the development of action plan leads to the practice or implementation which related to auditing and evaluating.
\end{abstract}

\section{KEYWORDS}

\section{e-Learning; Benchmarking; e-Learning Benchmarking Model}

\section{Introduction}

E-learning operation in the university level has been developed and expanded continuously in almost every part of the world. One method commonly used in the United States, Europe, Australia and New Zealand is to improve the quality of benchmarking e-learning which is useful for identifying organizational strengths and weaknesses with developing a strategic plan for e-learning as well as its quality assurance. Moreover, it can determine the extent of success from the e-learning operation. Changing concepts and improving e-learning, for example, elearning benchmarking in Australia is ACODE (Australasian Council on Open, Distance and E-learning) [1]. Has developed strategies for the implementation and also brought to the success in three aspects of the performance-operation result, management efficiency and elearning services improvement [2,3].

Among the European countries, England is a leader in e-learning benchmarking method in higher education. The Higher Education Academy (HEA) and the Joint Information Systems Committee (JISC) is a pioneering project of the initiative, and comparable performance in England [4]. The study of comparison in five benchmark- ing e-learning methods, ELTI (Embedding Learning Technologies Institutionally), MIT90s (developed by Massachusetts Institute of Technology in the 1990s), OBHE/ACU (Observatory for Borderless Higher Education/Association of Commonwealth Universities), Pic \& Mix (developed by Professor Paul Bacsich, the programme's consultant) and eMM (e-learning Maturity Model) Nazako Joanicjusz are analyzed and started in November 2005 [5]. The objective of this project is to create the standard, capacity and good practice in elearning as well as the issue of improving quality and the development of e-learning continuously. For the development of benchmarking e-learning model in higher education institutions in Thailand, it is derived from the concept of e-learning and theories that various scholars used to suggest including quality assurance, performance indicators and benchmarking in e-learning in foreign countries. This research plays an important part in the implementation of e-learning in higher education institutions, the country's quality standards as well as the creation of new knowledge in the context of e-learning to improve its quality. From the results, e-learning growth to other countries is progressive both in quantity and 
quality and it moves onward with the changes occurring in the future.

\section{Literature Review}

Benchmarking is a systematic and continuous developing process for evaluating institution's performance quality to determine how the different accepted famous organizations work by studying the best practice by setting standard indicators and comparing from the indicators and finally, apply the result to improve the performance quality both in producing and service processes [6-10].

\subsection{Elements of Benchmarking Model}

Academics have discussed the elements of benchmarking as followings:

Andersen and Pettersen and Camp discussed the elements of benchmarking that it started by setting a comparable performance team and then clearly defined the structure of the Executive management, the position and the role of each division to be flexible and consistent promotion of each other. Learn to observe the process of the Organization and understand the processes running in your own organization to identify methods and operating procedures to determine the criteria for selecting an organization that uses a pair of equivalent performance to determine indicators for comparable performance to select methods and tools to collect information to analyze data throughout the report and apply the results to continue to improve enterprise development [6,7].

Robere described setting up a team is an important element in the comparable performance as well as defining the compared Agency, collecting data and analyzing data on indicators, summarizing and reporting the results of operations and communications informing people in all levels through the Organization by using various methods to make final plans to perform the objectives of the organization. Finally make a plan to accomplish the organization's goal [9].

Camp mentioned the important component of comparable performance is to identify what elements we want to compare by considering missions from both organizations, how to collect the comparative organization, determining how to collect information and a variety of information gathering, analyzing, summarizing, implementing report and plans for future operation [7].

Kelly mentioned that to specify the elements of comparable performance we need to consider the functions in the operation of the team, choose a format that will make comparable academic performance documents and related information, pick a pair compared organization and appoint the comparable performance team, analyze data using statistical method, present the presentation was updated and how to perform the best (Best Practice), write a summary of a plan and publish a policy and finally, turning into action, work together is the policy in the last work together to hand coordination planned together to take a step towards to excellence [8].

\subsection{Steps of Benchmarking Model}

Andersen and Pettersen have divided benchmarking model into 5 steps. Plan is the most important process that will bring benchmarking to be successful and effective and get the good implementation. Search is the step to find the best comparative companies. An activity required in this step is to define the criteria for selecting potential comparative companies. Observe: the purpose of observing is to define and understand the performance process of the comparative companies to improve performance process in your own company. Analyses: to determine the gap of the process and analyze the problems that cause the gap and discuss the results of the data obtained to develop performance process, and Adapt: to improve operating process is necessity in comparable performance. To define the opportunity in improving and developing after getting the Best Practice, team needs to consider the elements of time and resource, and necessities of company, availability of personnel processes involved in developing and targeting must be able to measure and assess, to report operating results as a summary execution from the beginning until the end and to add some comments and further suggestions [6].

Robere and Associates Benchmarking Model have developed a format derived from the ideas of the comparable performance experts an experience in the field of quality more than 20 years. They have merged to bright out the strengths model as part of the model by combining the steps of Edward De Ming as following below. Plan-Select the process you want and provide comparable performance team. Do-Collect and analyze the data, examine the differences, advantages and strengths that have been found in the company. Study-Study systematically and inform involved people all findings of the benchmarking and set the targets. Action-Create action plan development [9].

Camp the main phases of comparable performance based on Camp's concept are divided into 5 phases. 1 - 4 phrases are comparable performance process and each phase is broken down totally into 10 procedures. Phase 5 has two additional steps to ensure that operation has operated effectively and achieved the goal. Phases and steps of benchmarking model consist of: Phase 1 Planning the operation. The purpose is to answer the 3 points, What, Who and How is to be benchmark? There are 3 sub-steps: Sub-step 1: identify what to compare. Sub-step 2: define which company that has the best practice. Sub-step 3: determine data and data collection method, the operator must plan and define the detailed operation procedures 
carefully to get the best information. Phase 2: Analysis phase: to analyze, compare and understand our company and to see the different data of comparative company. What are the weaknesses and strengths of comparative company, where is the best practice? How to bring the process to use with our company? Sub-step 4: set the performance space and take report results in our organization and compare with the comparative company in quantity or quality comparison. Sub-step 5: determine the plan or the level of operations in the future. Phase 3, Integration phase. In order to change or improve organization, integrating new techniques or new innovation is very important. Sub-step 6: communicate or inform the discovery to everyone in company to know the result and findings from the benchmarking. Sub-step 7: set operation's goals. Phase 4: action phrase Sub-step 8: planning development. Sub-step: monitoring and following up Sub-step: evaluating and comparing results with the standard criteria. Phase 5: Maturity, the operation in this phase is to make the best element, that is, the execution of all processes in the organization and competency development to participate at the same time [11].

Kelly there are 8 steps in educational benchmarking as follows: 1 . Decide to make a benchmarking by considering from function and its results. 2. Select the format or model to be com-pared by consulting from the documentation and relevant information, selection of a suitable performance compared with the job. 3. Select the comparative companies and assign the team to operate by choosing equivalent comparative company that has equivalent performance and same environment and assign the efficiency of personnel to take responsibility. 4. Select the appropriate comparable performance by studying and comparing the results of each process. 5. Compare possible results by creating with 3 steps: create a draft questionnaire, tryout and develop and use it to collect data at last. 6. Result comparison, there are 2 steps; statistic data analysis and comparing to find the space of the performance.7. Design new operation and set the targets. There are 2 steps; one is to define and create the models and the other one is to reduce the performance's gap in presenting new model to board committees to consider the new improved model. 8. Improving and developing. There are 3 steps, these are; take the suggestions and comments of the committees to improve and develop to be the best practice. Summarize plans and declares as the policies in cooperating and follow the action plan. The template is used to format your paper and style the text. All margins, column widths, line spaces, and text fonts are prescribed; please do not alter them. You may note peculiarities. For example, the head margin in this template measures proportionately more is customary. This measurement and others are deliberate, using specifications that anticipate your paper as one part of the entire proceedings, and not as an independent document. Please do not revise any of the current designations [8].

\section{Methodology}

\subsection{Study and Analyze Theoretical Concept}

Documents related to the elements and steps of benchmarking as follow:

- the benchmarking handbook: step-by-step instruction [6].

- Benchmarking: A system approach for continual improvement [9].

- Business Process Benchmarking: Finding and Implementing Best Practices [7].

- Benchmarking for School Improvement: A practical guide for comparing and achieving effectiveness [8].

\subsection{Opinion Interview and Confirming Data}

- Opinion interview and confirming data from the specialists about the elements of e-learning benchmarking to get suggestions and opinions about the elements and steps that related and suitable with e-learning benchmarking including data confirmation from the specialists. The researcher used the interview question covered the important weight and appropriateness of elements and steps of e-learning benchmarking.

- 5 representative samples who answered the questionnaire were chosen by using purposive sampling. Interview question was used as a tool for this research. Collecting and analyzing comments from the specialists based on the content validity comparing with theoretical concepts related to the issues and considered the appropriateness and consistency of data. Mean and SD were used as the statistical procedure to analyze data.

\section{Resullts}

The opinion interview and questionnaire results about the elements and steps of e-learning benchmarking were taken from five specialists and summarized shown in Tables 1 and 2 below.

The consideration results from the experts found that the elements of benchmarking consist of 8 elements as follow: 1) team/staffs 2) bench marking's title 3) comparative companies 4) benchmarking indicators 5) data collection method 6) analysis data and results 7) report of results 8) action plan development.

The result from the specialists found that the steps of benchmarking consist of 1) Plan includes team/staff, bench-marking model, benchmarking titles, benchmarking indicators, comparative companies and data collect- 
Table 1. Elements of e-Learning Benchmarking.

\begin{tabular}{cccc}
\hline Considering issues & Mean & S.D & Meaning \\
\hline team/staffs & 4.60 & 0.89 & Most appropriate \\
benchmarking title & 4.60 & 0.89 & Most appropriate \\
comparative companies & 4.60 & 0.89 & Most appropriate \\
benchmarking indicators & 4.60 & 0.89 & Most appropriate \\
data collection method & 4.60 & 0.89 & Most appropriate \\
analysis data and results & 4.40 & 1.34 & Most appropriate \\
report of results & 4.60 & 0.89 & Most appropriate \\
action plan development & 4.40 & 1.34 & Most appropriate \\
\hline
\end{tabular}

Table 2. Steps of e-Learning Benchmarking Model.

\begin{tabular}{cccc}
\hline Considering issues & Mean & S.D & Meaning \\
\hline Plan & & & \\
Team/staff & 4.80 & 0.45 & Most appropriate \\
Benchmarking model & 4.20 & 1.79 & appropriate \\
Benchmarking titles & 4.40 & 1.34 & appropriate \\
Benchmarking indicators & 4.40 & 1.34 & appropriate \\
Comparative companies & 4.40 & 1.34 & appropriate \\
Data collecting method & 4.20 & 1.79 & appropriate \\
Do & & & \\
Data and result analysis & 4.60 & 0.89 & Most appropriate \\
Report of results & 4.40 & 1.34 & appropriate \\
Best Practice & 4.40 & 1.34 & appropriate \\
Check & & & \\
Setting goals & 4.20 & 1.30 & appropriate \\
communication & 4.00 & 1.41 & appropriate \\
Act & & & \\
Writing or designing & 4.80 & 0.45 & Most appropriate \\
Implementation & 4.40 & 1.34 & appropriate \\
Evaluation and assessment & 4.60 & 0.89 & Most appropriate \\
\hline
\end{tabular}

ing method 2) Do in-cludes data and result analysis, report of results and best practice 3) Check includes setting goals, communication 4) Act includes writing or designing, implementation and evaluation and assessment.

The result of this paper shows that there are eight elements of e-learning benchmarking model: 1) team/ staffs 2) bench marking's title 3) comparative companies 4) benchmarking indicators 5) data collection method 6) analysis data and results 7) report of results and 8) action plan development. Moreover, four steps of benchmarking model will be used in this research. "Plan" is the step of setting team for benchmarking title and choosing the company to collect the benchmarking while "Do" is a field study in order to analyze and collect each indicator. The step "Check" presents the data to stakeholders and sets the purposes of action plan. Finally, "Act" which is the development of action plan leads to the practice or implementation which related to auditing and evaluating.

\section{Conclusion}

All research projects are ongoing, so the conclusion can explain the results of first stage which are partly from the main research of e-learning benchmarking model for higher education institutions. The researcher presented the eight elements as the key and continued with four steps of e-learning benchmarking. The results will contribute and encourage benchmarking techniques for using e-learning in higher education institutions which can help the operating staffs in using and developing an efficient e-learning for students. These also lead to the development of a good standard of e-learning and will be a good practice model in higher education institutions.

\section{Acknowledgements}

The support of this work by the Office of the Higher Education Commission, Thailand through a grant in the program "Strategic Scholarships for Frontier Research Network for the Ph.D. Program, Thai Doctoral degree" is gratefully acknowledged.

\section{REFERENCES}

[1] Australasian Council on Open, Distance and e-Learning. (ACODE), "Benchmarks for E-Learning in Universities and Guidelines for Use,” 2007.

http://www.acode.edu.au/benchmarks.php

[2] C. Sarojni, "Benefits of E-Learning Benchmarks: Australian Case Studies,” The Electronic Journal of E-Learning, Vol. 5, No. 1, 2007, pp. 11-20.

[3] H. Smith, M. Armstrong and S. Brown, "Benchmarking and Threshold Standards in Higher Education,” Kogan Page Limited, London, 1999.

[4] Higher Education Academy, "Challenges and Realizations from the Higher Education Academy/JISC Benchmarking and Pathfinder Programme: An End Programme Review by the Higher Education Academy, Evaluation and Dissemination Support Team,” 2008. http://elearning.heacademy.ac.th/webloogs/pathfinder/wp -content/uploads/2008/09/Bench_and_PathFinalReview2 0080926.pdf

[5] N. Joanicjusz, K. Z. Katarzyna, S.-P. Elzbieta and U. Joanna, "The General Concept of Benchmarking and its Application in Higher Education in Europe,” Higher Education in Europe, Vol. 34, 2009, pp. 3-4,

[6] B. Anderson and P.-G. Pettersen, "The Benchmarking Handbook: Step-By-Step Instruction,” Chapman \& Hall, London, 1996.

[7] R. C. Camp, "Business Process Benchmarking: Finding and Implementing Best Practices,” APQC Quality Press, Wisconsin, 1995.

[8] K. Anthony, "Benchmarking for School Improvement: A Practical Guide for Comparing and Achieving Effective- 
ness,” Routledge Famer, Taylor \& Frances Group, London, 2001.

[9] P. J. Robere, "Benchmarking: A System Approach for Continual Improvement,” Durakitbundit University Press, Bangkok, 2000.
[10] S. Tucker, "Benchmarking A Guide for Education," Corwin Press, California, 1996.

[11] R. C. Camp, "Global Cases in Benchmarking: Best Practices from Organizations around the World," APQC Quality Press, Wisconsin, 1998. 